338-5945

\title{
Acupuncture and Reiki as a Prevention Strategy of Burnout and Occupational Stress in Oncology
}

\author{
Manuela Santos ${ }^{1}$, Ana Joaquim*2, Ângela Bernardo ${ }^{1}$, Henrique Coelho ${ }^{3}$ and Rui Gomes ${ }^{4}$ \\ ${ }^{1}$ Nurse of Oncology Day Care of Hospital Center of Vila Nova de Gaia, (C \\ HVNG/E), Portugal
}

${ }^{2}$ Medical Doctor of Medical Oncology Department of CHVNG/E, Portugal

${ }^{3}$ Medical Doctor of Clinical Hematology Department of CHVNG/E, Portugal

${ }^{4}$ Assistant Professor in Psychology School of University of Minho, Portugal

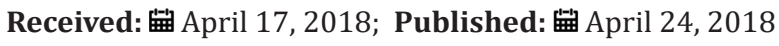

*Corresponding author: Ana Joaquim, Medical Doctor of Medical Oncology Department of CHVNG/E, Portugal

\begin{abstract}
Burnout is a professional syndrome associated with stress caused by overwork and is highly prevalent in healthcare professionals working with cancer patients. Our aim was to assess the role of complementary therapies, namely acupuncture and Reiki, in Burnout and Stress prevention of healthcare professionals working at an Oncology and Haematology Departments of a Portuguese hospital. Therefore, an experimental, cross-sectional study was designed wherein a sample of 16 participants underwent acupuncture and Reiki sessions. The Maslach's Burnout InventoryHuman Service Surveys (MBI-HSS) as well as the Stress Questionnaire for Health Professionals (SQHP) were completed by all participants before and after the intervention. Furthermore, they were also asked qualitative questions regarding their perceptions about these therapies. The results suggest that the complementary therapies used may have a role in the prevention of burnout and occupational stress.
\end{abstract}

Keywords: Burnout; Occupational stress; Oncology; Acupuncture; Reiki

Abbreviations: MBI-HSS: Maslach's Burnout Inventory-Human Service Surveys; SQHP: Stress Questionnaire for Health Professionals; CHVNG: Centro Hospital de Vila Nova de Gaia/Espinho

\section{Introduction}

Burnout is one of the health problems that occur most prominently among human service professionals. This syndrome was first identified in [1] by Freudenberger and defined as "a physical and emotional fatigue that leads to a loss of motivation for the work, which can evolve until the onset of feelings of failure [2]. In the following years other definitions have been proposed, highlighting the syndrome impact on the personal and professional dimension of the worker's life as well as the relationship of the health professional with his clients. Schaufeli e Greenglass [3] stated that Burnout is "a state of physical, emotional and mental exhaustion that results from long-term involvement in work situations that are emotionally demanding" [3]. When affected, human service professionals can fail to feel compassion for the suffering of others and stop giving them the care they need, particularly the emotional and communicational needs. In the same extent, professionals suffering from burnout tend to depart completely from their functions, which could result in serious damage to public health as it results in a waste of talent and training resources [4]. 
A study conducted by the European Young Oncologists from ESMO (2017) has shown that burnout is highly prevalent amongst European oncologists, being the cause for several negative consequences on quality of patient care, professional satisfaction and personal life. Acupuncture is an integral part of Traditional Chinese medicine and defined as a reflex therapy in which the nociceptive stimulus of the point of acupuncture triggers responses in other areas of the body (Schippers, 1993). Reiki is a complementary therapy that uses a healing system characterized by the laying on of hands on human bodies with the intention to re-establish the physical, mental and spiritual balance [5]. As both therapies have demonstrated efficacy in the treatment of anxiety and stress, a study was conducted in order to evaluate the role of these therapies in the Burnout and Stress prevention of healthcare professionals working in a busy Oncology and Hematology Department in a Portuguese hospital - Centro Hospital de Vila Nova de Gaia/Espinho (CHVNG).

\section{Method}

\section{Subjects and methods}

An experimental, cross-sectional study was conducted between April and June 2017 in accordance with the ethical standards of the IGH-GCP guidelines and the Declaration of Helsinki. Medical doctors, nurses and other healthcare staff of the Oncology and Haematology Department were invited to participate. Each participant underwent three simultaneous sessions of Acupuncture and Reiki during two months and completed the Maslach's Burnout Inventory - Human Service Surveys (MBI-HSS), previously translated to and validated in Portuguese [6], and the Stress Questionnaire for Health Professionals (SQHP), before and after the acupuncture and Reiki sessions, in order to collect comparative data about the burnout and stress situation of the healthcare professionals submitted to the experience. The data obtained was analysed using SPSS and their internal consistency assessed by the Alfa Cronbach measurement resulted in good consistency values (.70-.90). Statistical analysis was divided in a descriptive analysis and a multiple comparisons in between data collected before and after the attendance on the acupuncture and Reiki sessions.

On the multiple comparisons, all the non-parametric variables resulting from the implementation of the above mentioned instruments were tested by the Wilcoxon signed-rank test. In addition, two qualitative issues were addressed to participants with the aim of registering opinions about the effectiveness of acupuncture and Reiki. The results were submitted to the content analysis method [7].

\section{Results}

Sixteen physicians, nurses and other healthcare staff aged 44.3 years $(\mathrm{PD}=7.67)$ answered to MBI-HSS and the data collected revealed that Emotional Exhaustion followed by Personal Achievement are the main factors of burnout in their profession
(Table 1). Regarding to the intervention itself, and taking into account the fact that only three acupuncture and Reiki sessions were performed in each participant, data showed a slightly decline of the Burnout in each of the factors. Personal Achievement was the predicting variable that has decreased more significantly with an average decrease of $50 \%$. The non-parametric statistical hypothesis test used to compare the values of the sample after and before the experiment denoted the existence of asymptotic significance for the level of significance $\mu 0=, 05$. For the items Emotional Exhaustion and Depersonalization the null hypothesis was rejected being only retained when considering the repeated measures for Personal Achievement.

Table 1: Burnout values of the sample before (M1) and after (M2) acupuncture and Reiki.

\begin{tabular}{|c|c|c|c|}
\hline & & M1 & M2 \\
\hline \multirow{2}{*}{$\begin{array}{c}\text { BURNOUT } \\
\text { (prevalence) }\end{array}$} & Emotional Exhaustion & 7 & 5 \\
\cline { 2 - 4 } & Depersonalization & 3 & 2 \\
\cline { 2 - 4 } & Personal Achievement & 6 & 3 \\
\hline
\end{tabular}

The Wilcoxon signed-rank test for Burnout values of the sample did not show a statistically significant reduction in the burnout levels for the studied population. Similar results were also seen for the values referring to occupational stress, as shown in Table 2. As far as the participants' opinion regarding acupuncture and Reiki is concerned, the results revealed a positive development of the perception of the participants. In fact, before the beginning of the experiment the participants had very low expectations about these therapies. However, after three sessions the majority affirmed to be satisfied and showed willing to continue.

Table 2: Occupational Stress values of the sample before (M1) and after (M2) acupuncture and Reiki.

\begin{tabular}{|c|c|c|c|c|}
\hline & & M1 & M2 & p \\
\hline \multirow{4}{*}{$\begin{array}{c}\text { OCCUPATIONAL } \\
\text { STRESS }\end{array}$} & $\begin{array}{c}\text { Dealing with } \\
\text { customers }\end{array}$ & 2.4412 & 2.2990 & ns \\
\cline { 2 - 5 } (average levels) & $\begin{array}{c}\text { Professional } \\
\text { relationships }\end{array}$ & 2.1765 & 1.9676 & ns \\
\cline { 2 - 5 } & $\begin{array}{c}\text { Overwork } \\
\text { remuneration }\end{array}$ & 2.5147 & 2.3971 & ns \\
\cline { 2 - 5 } & \begin{tabular}{c} 
Training actions \\
\cline { 2 - 5 }
\end{tabular} & 2.1569 & 2.01186 & $\mathrm{~ns}$ \\
\cline { 2 - 5 } & Family problems & 1.6875 & 1.5735 & $\mathrm{~ns}$ \\
\hline
\end{tabular}

\section{Discussion}

A decrease in burnout and stress levels in our sample after acupuncture and Reiki treatment was determined, although the reduction was not significant. Considering these results it is important not to overlook some aspects and conditions under which the experiment was conducted, namely the difficulty in building a solid sample and to ensure that all participants received the same number of treatments in the same period of time, due to constraints of working hours of the investigators. In fact, it was 
necessary to conjugate the available time of all participants with the time that the acupuncture and Reiki techniques, only two for the whole sample, had to perform the sessions. These difficulties prevented the completion of the initially desired five treatment sessions, which obviously, impact the results obtained. As stated by the European Young Oncologists from ESMO (2017), burnout is the cause for many negative consequences on the quality of patient care, professional satisfaction and personal life, and it is a health problem that most frequently affects human service professionals [4], a fact that was also verified in the present study sample (Table $3)$.

Table 3: Content analysis to the perception about acupuncture and reiki.

\begin{tabular}{|c|c|c|}
\hline & Before & After \\
\hline \multirow{3}{*}{$\begin{array}{l}\text { Acupuncture/ } \\
\text { Reiki } \\
\text { perception } \\
\text { (Qualitative } \\
\text { analysis) }\end{array}$} & "Feel to Believe " (E1) & $\begin{array}{c}\text { "Peace; Tranquillity; } \\
\text { Lightness; Levitate" (E3) }\end{array}$ \\
\hline & $\begin{array}{l}\text { "Well let's see what this } \\
\text { is! I'm not a believer!" } \\
\text { (E7) }\end{array}$ & $\begin{array}{l}\text { "Relaxation; Welfare; } \\
\text { Equilibrium, Alternative; } \\
\text { Reencounter" (E9) }\end{array}$ \\
\hline & $\begin{array}{l}\text { "Curiosity. Expectation } \\
\text { to obtain good results" } \\
\text { (E12) }\end{array}$ & $\begin{array}{l}\text { "I felt freer and calmer } \\
\text { after a few sessions. I'm } \\
\text { so sorry that I cannot } \\
\text { do more. I would love to } \\
\text { continue!" (E11) }\end{array}$ \\
\hline
\end{tabular}

The results of our study suggest that acupuncture and Reiki have potential to reduce the prevalence of burnout and occupational stress related to cancer care. Furthermore, we underline the qualitative opinions registered among participants when completing the questionnaire, after acupuncture and Reiki sessions. Initially all felt a mixture of curiosity and scepticism but, in the end, all unanimously express their willingness to continue to have acupuncture and Reiki treatments because this experience make them to restore inner peace and balance. Furthermore, it should be stressed that participants reported, at the end of the treatment, an improvement of debilitating symptoms such as migraines, premenstrual syndrome, breathing difficulties, nausea related to pregnancy and osteoarticular pain. Those findings, although not being part of the main objective of the study, highlight other positive aspects of acupuncture and Reiki with regard to the promotion of physical and emotional well-being amongst Oncology and Hematology professionals [8].

\section{Conclusions}

The obtained results are not sufficient to demonstrate the benefits of acupuncture and Reiki as supportive therapies in the burnout and occupational stress prevention of healthcare professionals working with cancer patients. Nevertheless, they pave the way for new studies, with larger samples and therapy sessions, that adequately assess the real impact of these alternative therapies in health and well-being of healthcare professionals in oncology.

\section{References}

1. Freudenberger HJ (1974) Staff Burn-Out. Journal of Social Issues 30(1): 159-165.

2. Maslach C, Jackson S (1981) The measurement of experienced burnout. Journal of Occupational Behaviour 2: 99-111.

3. Schaufeli WB, Greenglass ER (2001) Introduction to Special Issue on Burnout and Health. Psychology and Health 16: 501-510.

4. Negash S, Sahin S (2011) Compassion fatigue in marriage and family therapists: Implications for therapists and clients. Journal of Marital \& Family Therapy 37(1): 1-13.

5. Freitag VL, Dalmolin IS, Badke MR, Andrade A (2014) Benefícios do reiki em população Idosa com dor Crónica. [Benefits of Reiki in the Elderly Population with Chronic Pain]. Texto Contexto Enferm 23(4): 10321040.

6. Gonzaga AL (2003) A validação do Maslach Burnout inventory em língua portuguesa: Um estudo exploratório [The validation of Maslach Inventory in portuguese: an exploratory study], Brazil.

7. Minayo, Maria Cecília de Souza (1996) Social Research: Theory, Method and Creativity. [Social Research: Theory, Method and Creativity] $6^{\text {th }}$ edn. Petrópolis: Editora Vozes, Brazil.

8. S Banerjee, R Califano, J Corral, E de Azambuja, L De Mattos Arruda, et al (2017) Professional burnout in European young oncologists: results of the European Society for Medical Oncology (ESMO) Young Oncologists Committee Burnout Survey. Annals of Oncology 28(7): 1590-1596.

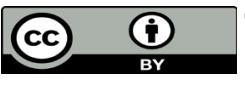

This work is licensed under Creative Commons Attribution 4.0 License

To Submit Your Article Click Here:

Submit Article

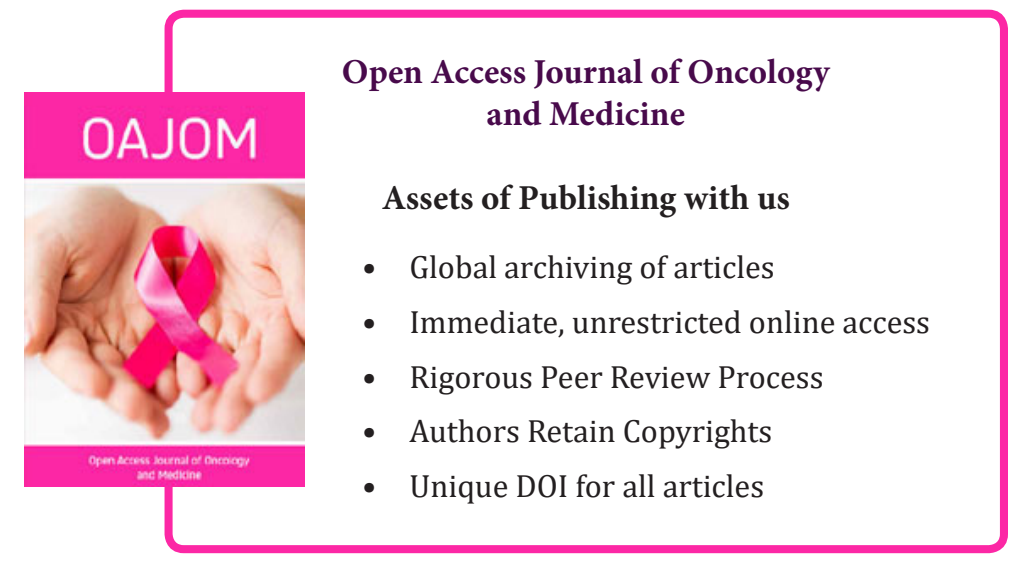

